\title{
Spatial Orientation and Mechanical Properties of the Human Trachea: A Computed Tomography Study
}

\author{
Alberto Zanella MD, Massimo Cressoni MD, Daniela Ferlicca MD, Chiara Chiurazzi MD, \\ Myra Epp, Cristina Rovati MD, Davide Chiumello MD, Antonio Pesenti MD, \\ Luciano Gattinoni MD, and Theodor Kolobow MD
}

\begin{abstract}
BACKGROUND: The literature generally describes the trachea as oriented toward the right and back, but there is very little detailed characterization. Therefore, the aim of this study was to precisely determine the spatial orientation and to better characterize the physical properties of the human trachea. METHODS: We analyzed lung computed tomography scans of 68 intubated and mechanically ventilated subjects suffering from acute lung injury/ARDS at airway pressures $\left(\mathbf{P}_{a w}\right)$ of 5,15 , and $45 \mathrm{~cm} \mathrm{H}_{2} \mathrm{O}$. At each $P_{a w}$, the inner edge of the trachea from the subglottal space to the carina was captured. Tracheal length and diameter were measured. Tracheal orientation and compliance were estimated from processing barycenter and surface tracheal sections. RESULTS: Tracheal orientation at a $\mathrm{P}_{\mathrm{aw}}$ of $5 \mathrm{~cm} \mathrm{H}_{2} \mathrm{O}$ showed a $4.2 \pm 5.3^{\circ}$ angle toward the right and a $20.6 \pm 6.9^{\circ}$ angle downward toward the back, which decreased significantly while increasing $P_{\text {aw }}\left(19.4 \pm 6.9^{\circ}\right.$ at $15 \mathrm{~cm} \mathrm{H}_{2} \mathrm{O}$ and $17.1 \pm 6.8^{\circ}$ at $\left.45 \mathrm{~cm} \mathrm{H}_{2} \mathrm{O}, P<.001\right)$. Tracheal compliance was $0.0113 \pm 0.0131 \mathrm{~mL} / \mathrm{cm} \mathrm{H} \mathrm{H}_{2} \mathrm{O} / \mathrm{cm}$ of trachea length from 5 to $15 \mathrm{~cm} \mathrm{H}_{2} \mathrm{O}$ and $0.004 \pm$ $0.0041 \mathrm{~mL} / \mathrm{cm} \mathrm{H}_{2} \mathrm{O} / \mathrm{cm}$ of trachea length from 15 to $45 \mathrm{~cm} \mathrm{H}_{2} \mathrm{O}(P<.001)$. Tracheal diameter was $19.6 \pm 3.4 \mathrm{~mm}$ on the medial-lateral axis and $21.0 \pm 4.3 \mathrm{~mm}$ on the sternal-vertebral axis. CONCLUSIONS: The trachea is oriented downward toward the back at a $20.6 \pm 6.9^{\circ}$ angle and slightly toward the right at a $4.2 \pm 5.3^{\circ}$ angle. Understanding tracheal orientation may help in enhancing postural drainage and respiratory physiotherapy, and knowing the physical properties of the trachea may aid in endotracheal tube cuff design. Key words: trachea anatomy; trachea orientation. [Respir Care 2015;60(4):561-566. (c) 2015 Daedalus Enterprises]
\end{abstract}

\section{Introduction}

The trachea is commonly described only as oriented toward the right and back. ${ }^{1,2}$ There is little information in the literature describing its spatial orientation or physical characteristics.

Drs Zanella, Ferlicca, and Pesenti are affiliated with the Dipartimento di Scienze della Salute, Università di Milano-Bicocca, Ospedale San Gerardo Nuovo dei Tintori, Monza, Italy. Drs Cressoni, Gattinoni, Chiurazzi, and Rovati are affiliated with the Dipartimento di Fisiopatologia Medico-Chirurgica e dei Trapianti, Università degli Studi di Milano, Milan, Italy. Drs Chiumello and Gattinoni are affiliated with the Dipartimento di Anestesia, Rianimazione (Intensiva e Subintensiva) e Terapia del Dolore, Fondazione Istituto di Ricovero e Cura a Carattere Scientifico Ca' Granda, Ospedale Maggiore Policlinico, Milan, Italy. Drs Zanella, Cressoni, and Kolobow and Ms Epp are affiliated with the National Institutes of Health, National Heart, Lung, and Blood Institute, Bethesda, Maryland.
Tracheal mucus transport is influenced by gravitational force $^{3}$; an orientation of the trachea/endotracheal tube (ETT) below the horizontal plane (Trendelenburg position) prevented ventilator-associated pneumonia (VAP) in

\footnotetext{
This study was supported by the Ministero dell'Istruzione, dell'Università e della Ricerca (MIUR). The authors have disclosed no conflicts of interest.

Dr Ferlicca presented a version of this paper at SMART (Simposio Mostra Anestesia Rianimazione e Terapia Intensiva) 2013, held May 10, 2013, in Milan, Italy.

Correspondence: Alberto Zanella MD, Dipartimento di Scienze della Salute, Università di Milano-Bicocca, Ospedale San Gerardo Nuovo dei Tintori, via Donizetti 106, 20900 Monza, Italy. E-mail: zanella. alb@gmail.com.
}

DOI: $10.4187 /$ respcare.03479 
both sheep and swine models following prolonged mechanical ventilation. The trachea/ETT orientation promoted the outward drainage of bacteria-laden mucus, avoiding bacterial translocation from the oropharynx into the lungs. ${ }^{4,5}$ Detailed knowledge of the orientation of the human trachea is therefore imperative for VAP prevention strategy in intubated patients. ${ }^{6}$

In this retrospective analysis of computed tomography (CT) images, the length, diameter, orientation, and compliance of tracheas from mechanically ventilated subjects at different airway pressures $\left(\mathrm{P}_{\mathrm{aw}}\right)$ were investigated.

\section{Methods}

Data from a multi-center CT scan database of a previously published study were analyzed. ${ }^{7}$ The study was approved by the institutional review board of each hospital, and written informed consent was obtained according to the national regulations of the participating institutions in Italy, Germany, and Chile.

Sixty-eight mechanically ventilated subjects with acute lung injury/ARDS underwent whole-lung CT scanning at 3 different airway pressures $\left(5\right.$ and $15 \mathrm{~cm} \mathrm{H}_{2} \mathrm{O}$ endexpiratory pause and $45 \mathrm{~cm} \mathrm{H}_{2} \mathrm{O}$ end-inspiratory pause).

Subjects were enrolled if they met the criteria of the American-European Consensus Conference on $\mathrm{ARDS}^{8}$ for acute lung injury $\left(\left[\mathrm{P}_{\mathrm{aO}_{2}} / \mathrm{F}_{\mathrm{IO}_{2}}\right]\right.$ of $\left.<300 \mathrm{~mm} \mathrm{Hg}\right)$, with bilateral pulmonary infiltrates on the chest radiograph and no clinical evidence of left atrial hypertension (defined by a pulmonary-capillary wedge pressure of $\leq 18 \mathrm{~mm} \mathrm{Hg}$, if measured). The exclusion criteria were $<16$ y of age, pregnancy, and COPD according to the subject's medical history. Immediately before each CT session, a recruitment maneuver (ie, a sustained inflation of the lungs to higher $\mathrm{P}_{\mathrm{aw}}$ and volumes than those obtained during tidal ventilation) was performed in which the subject underwent ventilation for $2 \mathrm{~min}$ (pressure control mode at an inspiratory plateau pressure of $45 \mathrm{~cm} \mathrm{H}_{2} \mathrm{O}, \mathrm{P}_{\mathrm{aw}}$ of $5 \mathrm{~cm}$ $\mathrm{H}_{2} \mathrm{O}$, breathing frequency of 10 breaths/min, and a $1: 1$ inspiration-to-expiration ratio). After the recruitment maneuver, a $\mathrm{P}_{\mathrm{aw}}$ of 5 or $15 \mathrm{~cm} \mathrm{H}_{2} \mathrm{O}$ was randomly applied. The tidal volume $(8-10 \mathrm{~mL} / \mathrm{kg}$ of predicted body weight), $\mathrm{F}_{\mathrm{IO}_{2}}$, and breathing frequency were identical to the values used in everyday clinical treatment. A whole-lung CT scan was performed at an inspiratory plateau pressure of $45 \mathrm{~cm} \mathrm{H}_{2} \mathrm{O}$, during an end-inspiratory pause (ranging from 15 to $25 \mathrm{~s}$ ), and thereafter at $\mathrm{P}_{\mathrm{aw}}$ of 5 and $15 \mathrm{~cm} \mathrm{H}_{2} \mathrm{O}$ applied randomly during an end-expiratory pause (ranging from 15 to $25 \mathrm{~s}$ ). The CT scanner was set as follows: collimation, $5 \mathrm{~mm}$; interval, $5 \mathrm{~mm}$; bed speed, $15 \mathrm{~mm} / \mathrm{s}$; voltage, $140 \mathrm{kV}$; and current, $240 \mathrm{~mA}$. During each CT scan, the endotracheal tube cuff was inflated at a pressure greater than the maximal pressure used during the recruitment maneuver (ie, $>45 \mathrm{~cm} \mathrm{H}_{2} \mathrm{O}$ ).

\section{QUICK LOOK}

\section{Current knowledge}

The human trachea is commonly described only as oriented dorsally toward the right. There is little characterization of the trachea in terms of its spatial orientation or physical characteristics and how these impact both mucus clearance and the risk of pneumonia.

\section{What this paper contributes to our knowledge}

Data from computed tomography suggest that the trachea is oriented downward toward the back at a $20^{\circ}$ angle and slightly to the right at a $4^{\circ}$ angle. Understanding tracheal orientation may help to enhance postural drainage, and knowing the physical trachea properties may be useful for endotracheal tube cuff design.

For analysis, the inner edge of the trachea was manually drawn in each cross-sectional image (from the subglottal space to the carina) using Maluna 3 (University of Mannheim, Mannheim, Germany). The data were analyzed with SoftEfilm (www.elekton.it, Accessed October 30, 2014).

The CT scans were composed of a finite number of slices along the apex-base axis $(\sim 50$ at end-expiratory pressure, $\mathrm{P}_{\mathrm{aw}}$ of $5 \mathrm{~cm} \mathrm{H}_{2} \mathrm{O}$ ). Each trachea was divided into 10 sections on the medial-lateral axis (Fig. 1, A and B) and then divided into 10 sections of equal length along the apex-base axis. Since voxel dimensions are discrete, this created discrete quantities of 5-mm high CT planes (ie, if the lung CT scan is composed of 47 slices, 7 sections composed of eleven 5-mm high planes and 3 sections composed of ten 5-mm high planes). To smooth the data set without voxel interpolation, each 5-mm high CT plane was substituted with 10 identical 0.5 -mm CT planes; therefore, using 500 slices instead of 50 slices allowed a smoothing of $90 \%$ of the voxel attribution imbalance.

In each section, the barycenter along the 3 axes (coronal, frontal, and sagittal planes) was computed as: (1) barycenter on the medial-lateral axis $(\mathrm{mm})=$ sum of positions on the medial-lateral axis/( $n$ voxels), (2) barycenter on the apex-base axis $(\mathrm{mm})=$ sum of positions on the apex-base axis/( $n$ voxels), and (3) barycenter on the sternal-vertebral axis $(\mathrm{mm})=$ sum of positions on the sternal-vertebral axis/( $n$ voxels). Tracheal displacement along each axis was defined as: (4) tracheal displacement $(\mathrm{mm})=$ barycenter $(\mathrm{mm})$ of section $1-$ barycenter $(\mathrm{mm})$ of section $n$.

On the coronal plane, it was possible to draw a rightangle triangle with, as cathetus, the distance between the barycentric coordinates of 2 sections on the lung mediallateral axis and the distance between the barycentric coordinates of 2 sections on the lung apex-base axis (see 


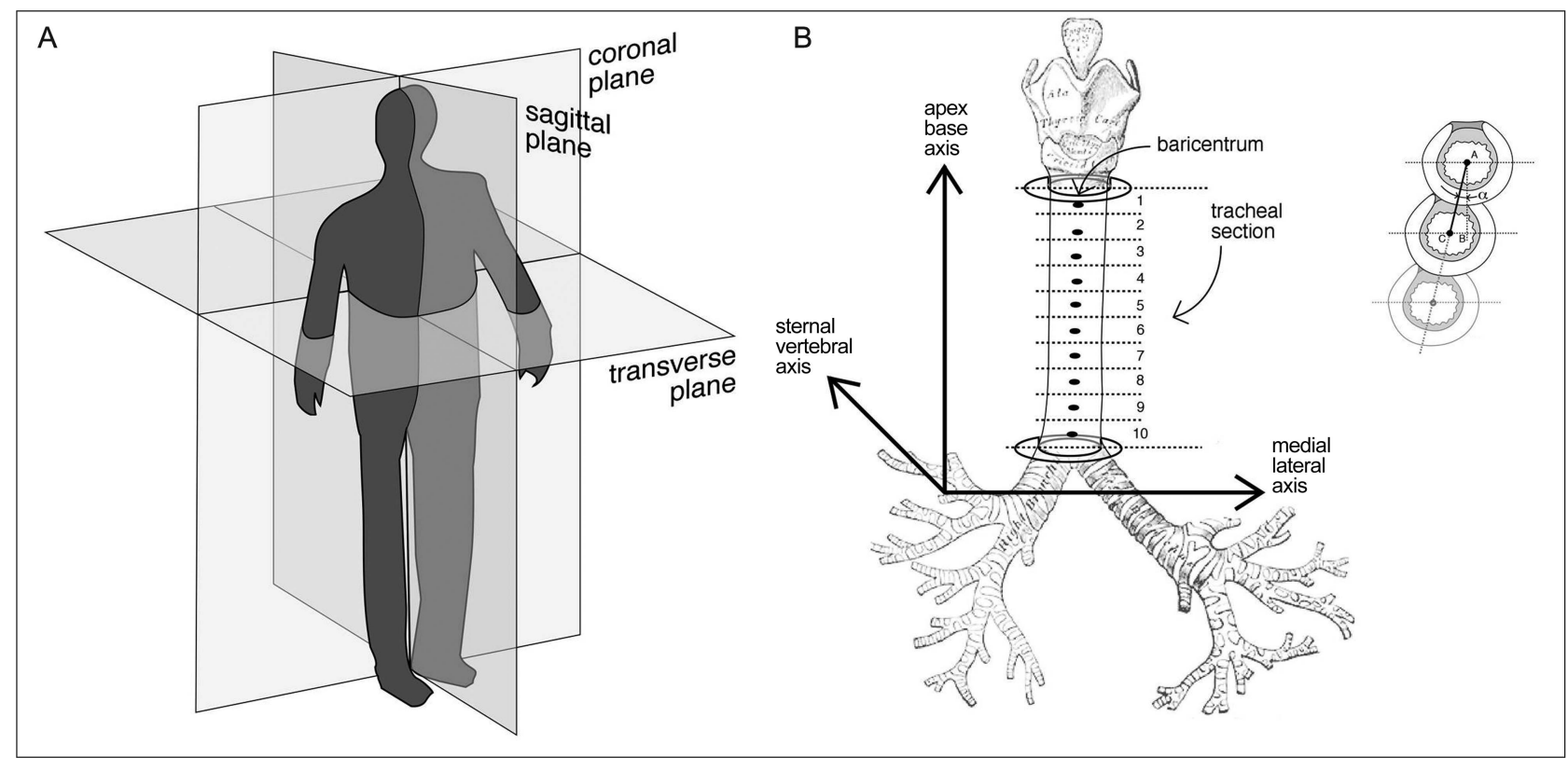

Fig. 1. A: The 3 different planes: sagittal, coronal, and transverse. B: The trachea divided into 10 sections, computed barycenter of each section along the 3 axes, and calculated tracheal displacement and tracheal angles on the coronal and sagittal planes.

Fig. 1). It follows that the tracheal angle on the coronal plane is: (5) angle on the coronal plane $=$ arctan (tracheal displacement on the medial-lateral axis $[\mathrm{mm}]$ between sections 1 and 10/tracheal displacement on the lung apex-base axis [mm] between sections 1 and 10).

In the same way it was possible to compute the tracheal angle on the sagittal plane (Fig. 2): (6) angle on the sagittal plane $=\arctan$ (tracheal displacement on the sternalvertebral axis [mm] between sections 1 and 10/tracheal displacement on the apex-base axis $[\mathrm{mm}]$ between sections 1 and 10).

Tracheal diameters and compliance were computed on sections 7 and 8 , which represent $\sim 1 \mathrm{~cm}$ of trachea length located $1 \mathrm{~cm}$ above the carina. These slices were selected because they are always below the ETT cuff, and in this position, the trachea maintains its shape, whereas immediately above the carina, the trachea elongates along the coronal plane. Tracheal compliance (normalized per $\mathrm{cm}$ of length) was calculated as the ratio between the increase in tracheal gas volume $(\mathrm{mL})$ in sections 7 and 8 and the increase in $\mathrm{P}_{\mathrm{aw}}$ (5-15 and 15-45 $\mathrm{cm} \mathrm{H}_{2} \mathrm{O}$, respectively).

\section{Statistical Analysis}

Data are expressed as mean \pm SD. Tracheal displacements, angles, diameters, and compliances at different $\mathrm{P}_{\mathrm{aw}}$ were compared with the Friedman repeated-measures test; the Tukey correction was used for multiple comparisons. Statistical analysis was performed with the program $\mathrm{R}$ (http://www.R-project.org, Accessed October 30, 2014).

\section{Results}

Subjects were: $49 \%$ females, $55 \pm 17$ y old, body mass index of $25 \pm 5 \mathrm{~kg} / \mathrm{m}^{2}$, Simplified Acute Physiology Score II of $37 \pm 11, \mathrm{P}_{\mathrm{aO}_{2}} / \mathrm{F}_{\mathrm{IO}_{2}}$ of $200 \pm 77 \mathrm{~mm} \mathrm{Hg}, \mathrm{P}_{\mathrm{aCO}_{2}}$ of $42 \pm 4 \mathrm{~mm} \mathrm{Hg}$, and expiratory minute volume of $9.8 \pm 3 \mathrm{~L} / \mathrm{min}^{7}$

Tracheal lengths studied were $84 \pm 19 \mathrm{~mm}$. The total tracheal gas volume was $19.1 \pm 7.6 \mathrm{~mL}$ at a $\mathrm{P}_{\mathrm{aw}}$ of $5 \mathrm{~cm} \mathrm{H}_{2} \mathrm{O}$. It significantly increased to $22.4 \pm 9.1$ and $26.3 \pm 9.9 \mathrm{~mL}$ at 15 and $45 \mathrm{~cm} \mathrm{H}_{2} \mathrm{O}(P<.001)$, respectively.

Tracheal orientation at a $\mathrm{P}_{\text {aw }}$ of $5 \mathrm{~cm} \mathrm{H}_{2} \mathrm{O}$ showed a $4.2 \pm 5.3^{\circ}$ angle toward the right on the coronal plane corresponding to a tracheal displacement of $6.2 \pm 7.6 \mathrm{~mm}$ (see Fig. 2A), and a $20.6 \pm 6.9^{\circ}$ angle corresponding to a displacement of $32.2 \pm 11.0 \mathrm{~mm}$ downward toward the back on the sagittal plane (see Fig. 2B). Tracheal displacements at $\mathrm{P}_{\mathrm{aw}}$ of 15 and $45 \mathrm{~cm} \mathrm{H}_{2} \mathrm{O}$ are reported in Table 1 . The angle on the coronal plane did not significantly change with increasing $\mathrm{P}_{\mathrm{aw}}(P=.56)$, whereas the angle on the sagittal plane significantly decreased with increasing $\mathrm{P}_{\mathrm{aw}}$ $(P<.001)$.

Tracheal diameters (sections 7 and 8) showed, on the coronal plane, a slight but significant increase with increasing $\mathrm{P}_{\mathrm{aw}}$, whereas on the sagittal plane, the increase was more significant (Table 2). Tracheal compliance (sections 7 and 8) was $0.0113 \pm 0.0131 \mathrm{~mL} / \mathrm{cm} \mathrm{H}_{2} \mathrm{O} / \mathrm{cm}$ of trachea length at a $\mathrm{P}_{\mathrm{aw}}$ of 5-15 $\mathrm{cm} \mathrm{H}_{2} \mathrm{O}$ and $0.004 \pm$ 

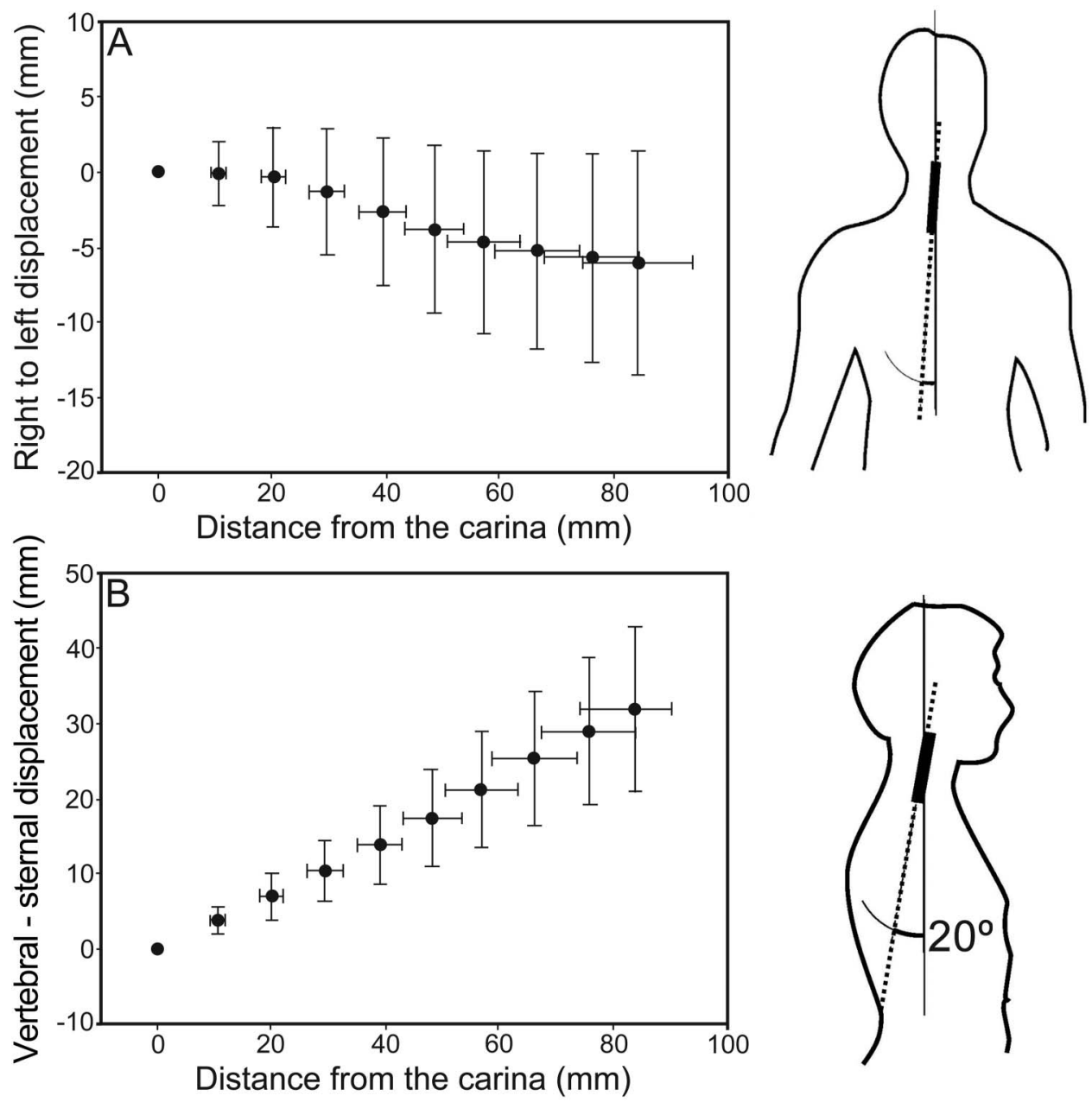

Fig. 2. A: Tracheal orientation on the coronal plane. The silhouette with the superimposed trachea shows the average angle of tracheal orientation (4.2 $\pm 5.3^{\circ}$ angle downward toward the right). B: Tracheal orientation on the sagittal plane. The silhouette with the superimposed trachea shows the average angle of tracheal orientation ( $20.6 \pm 6.9^{\circ}$ angle downward toward the back). Horizontal and vertical bars denote SD.

$0.0041 \mathrm{~mL} / \mathrm{cm} \mathrm{H}_{2} \mathrm{O} / \mathrm{cm}$ of trachea length at a $\mathrm{P}_{\mathrm{aw}}$ of $15-$ $45 \mathrm{~cm} \mathrm{H}_{2} \mathrm{O}$.

\section{Discussion}

The results obtained on tracheal orientation agree with literature data that describe the trachea as a tube orientated toward the back and right. The calculations showed a $4.2 \pm 5.3^{\circ}$ angle toward the right and a $20.8 \pm 6.7^{\circ}$ angle toward the back at a $\mathrm{P}_{\mathrm{aw}}$ of $5 \mathrm{~cm} \mathrm{H}_{2} \mathrm{O}$. At higher $\mathrm{P}_{\mathrm{aw}}$, both angles decreased. The relevant angle toward the back implies a gravitational movement of secretions toward the lungs in a supine position and toward the mouth in a prone position. These results are compatible with the finding of ETT obstructions as a complication of a prone position ${ }^{9}$ and the observed reduction in VAP incidence in a prone position. ${ }^{10,11}$ Animal models of VAP have consistently found an association between the development of VAP and an orientation of the trachea/ETT below the horizontal plane. ${ }^{3-5,12}$

The translation of experimental results obtained in animal models in the clinical setting implies the understanding of the anatomical differences between humans and swine/sheep. In quadrupeds, the oral cavity is directly aligned with the pharynx and the tracheal opening, whereas in humans, the mouth forms a $90^{\circ}$ angle with the pharynx. Thus, to utilize gravitational drainage of secretions and prevent aspiration, patients could be positioned prone or on their side to orient the trachea/ETT below the horizontal plane. When a patient is in a lateral or recovery position, being rotated on the left side would be more effective in preventing aspiration; to achieve the same effectiveness on the right side, it would require adding some degrees of Trendelenburg positioning. There is no conclusive evidence that the reduction of aspiration obtained with a prone position results in a significantly decreased rate of VAP 
Table 1. Summary of Tracheal Orientation With Increasing $\mathrm{P}_{\mathrm{aw}}$ of 5, 15, and $45 \mathrm{~cm} \mathrm{H}_{2} \mathrm{O}$

\begin{tabular}{|c|c|c|c|c|}
\hline & $\begin{array}{c}\text { Angle on } \\
\text { sagittal plane }\end{array}$ & $\begin{array}{l}\text { Tracheal displacement } \\
\text { on sagittal plane }(\mathrm{mm})\end{array}$ & $\begin{array}{c}\text { Angle on } \\
\text { coronal plane }\end{array}$ & $\begin{array}{l}\text { Tracheal displacement } \\
\text { on coronal plane }(\mathrm{mm})\end{array}$ \\
\hline \multicolumn{5}{|l|}{$\mathrm{P}_{\mathrm{aw}}$} \\
\hline $5 \mathrm{~cm} \mathrm{H}_{2} \mathrm{O}$ & $20.6 \pm 6.9^{\circ}$ & $31.8 \pm 11$ & $4.2 \pm 5.3^{\circ}$ & $6.2 \pm 7.6$ \\
\hline $15 \mathrm{~cm} \mathrm{H}_{2} \mathrm{O}$ & $19.4 \pm 6.9^{\circ} *$ & $30.7 \pm 11.1^{*}$ & $3.9 \pm 5.1^{\circ}$ & $5.9 \pm 7.7$ \\
\hline $45 \mathrm{~cm} \mathrm{H}_{2} \mathrm{O}$ & $17.1 \pm 6.9^{\circ} * \dagger$ & $38.2 \pm 11.2^{* \dagger}$ & $3.8 \pm 4.9^{\circ}$ & $6.2 \pm 7.7$ \\
\hline$P$ (between $\mathrm{P}_{\mathrm{aw}}$ ) & $<.001$ & $<.001$ & 0.56 & 0.45 \\
\hline \multicolumn{5}{|c|}{$\begin{array}{l}\text { Angles and tracheal displacements between airway pressures ( } \mathrm{P}_{\text {aw }} \text { ) were compared with the Friedman test for repeated measures, and the Tukey correction was applied for multiple comparisons. } \\
\begin{array}{l}* \\
\dagger\end{array}<.05 \text { vs } \mathrm{P}_{\text {aw }} \text { of } 5 \mathrm{~cm} \mathrm{H}_{2} \mathrm{O} \text {. } \\
\dagger P<.05 \text { vs } \mathrm{P}_{\text {aw }} \text { of } 15 \mathrm{~cm} \mathrm{H}_{2} \mathrm{O} \text {. }\end{array}$} \\
\hline
\end{tabular}

Table 2. Summary of Tracheal Diameters Measured at Sections 7 and 8 With Increasing $\mathrm{P}_{\text {aw }}$ of 5,15 , and $45 \mathrm{~cm} \mathrm{H}_{2} \mathrm{O}$

\begin{tabular}{|c|c|c|}
\hline & $\begin{array}{l}\text { Trachea diameter } \\
\text { of sagittal plane } \\
(\mathrm{mm})\end{array}$ & $\begin{array}{l}\text { Trachea diameter } \\
\text { of coronal plane } \\
(\mathrm{mm})\end{array}$ \\
\hline \multicolumn{3}{|l|}{$\mathrm{P}_{\mathrm{aw}}$} \\
\hline $5 \mathrm{~cm} \mathrm{H}_{2} \mathrm{O}$ & $19.6 \pm 3.5$ & $21.0 \pm 4.3$ \\
\hline $15 \mathrm{~cm} \mathrm{H}_{2} \mathrm{O}$ & $20.2 \pm 3.5^{*}$ & $22.3 \pm 4.3 *$ \\
\hline $45 \mathrm{~cm} \mathrm{H}_{2} \mathrm{O}$ & $20.4 \pm 3.3^{* \dagger}$ & $23.6 \pm 4.4 * \dagger$ \\
\hline$P$ (between $\mathrm{P}_{\mathrm{aw}}$ ) & $<.001$ & $<.001$ \\
\hline \multicolumn{3}{|c|}{$\begin{array}{l}\text { Tracheal diameters were compared with one-way analysis of variance for repeated measures; } \\
\text { the Tukey correction was applied for multiple comparisons. } \\
* P<.05 \text { vs } \mathrm{P}_{\mathrm{aw}} \text { of } 5 \mathrm{~cm} \mathrm{H}_{2} \mathrm{O} \text {. } \\
\dagger P<.05 \text { vs } \mathrm{P}_{\mathrm{aw}} \text { of } 15 \mathrm{~cm} \mathrm{H}_{2} \mathrm{O} \text {. } \\
\mathrm{P}_{\mathrm{aw}}=\text { airway pressure }\end{array}$} \\
\hline
\end{tabular}

in mechanically ventilated patients with respiratory failure, ${ }^{13}$ whereas a randomized trial comparing semirecumbent and lateral-Trendelenburg positions with intubated and mechanically ventilated subjects is currently ongoing (http://compartint.net/gravityvaptrial/joomla/, Accessed October 30, 2014).

Characterization of the physical properties of the trachea may be relevant for the design of new ETT cuffs. ${ }^{14-16}$ The trachea is a semirigid tube that connects the larynx to the main bronchi to allow the passage of air. It is composed of 15-20 C-shaped cartilaginous rings, opened dorsally, where a membranous wall (pars membranacea) completes the ring. The internal diameter is $\sim 25 \mathrm{~mm}$, and the length is $\sim 12 \mathrm{~cm}$.

As shown in this study regarding tracheal compliance, the pars membranacea is much more flexible than the cartilaginous rings. With increasing $\mathrm{P}_{\mathrm{aw}}$, the trachea was observed to deform and dilate, especially on the posterior side. Therefore, once the ETT cuff is inflated inside the trachea, the pressure exerted might differ on the posterior and anterior sides. Moreover, the low compliance observed in the applied $\mathrm{P}_{\mathrm{aw}}$ range allows us to model the trachea as a semirigid body, which is unlikely to significantly affect the efficiency of protective ventilation with low tidal vol- umes. The main limitation of the data regarding tracheal compliance is that the section of the trachea with the ETT cuff was already deformed when the ETT cuff was inflated at a pressure slightly $>45 \mathrm{~cm} \mathrm{H}_{2} \mathrm{O}$ during the recruitment maneuver.

\section{Conclusions}

The trachea is oriented with a $4.2 \pm 5.3^{\circ}$ angle toward the right and a $20.6 \pm 6.9^{\circ}$ angle toward the back. This information can be useful in the prevention of pulmonary aspiration and VAP and also in all pathological conditions that require strategies to promote the clearance of oropharyngeal and tracheal secretions.

\section{ACKNOWLEDGMENTS}

We thank Simone Sosio MD (Dipartimento di Scienze della Salute, Università di Milano-Bicocca, Ospedale San Gerardo Nuovo dei Tintori, Monza, Italy) for the graphic art.

\section{REFERENCES}

1. Balboni GC. Anatomia umana, 3rd edition. Milan: Edi.Ermes; 1990.

2. Standring S. Gray's anatomy: the anatomical basis of clinical practice, 40th edition. New York: Elsevier Health Sciences; 2008.

3. Li Bassi G, Zanella A, Cressoni M, Stylianou M, Kolobow T. Following tracheal intubation, mucus flow is reversed in the semirecumbent position: possible role in the pathogenesis of ventilatorassociated pneumonia. Crit Care Med 2008;36(2):518-525.

4. Panigada M, Berra L, Greco G, Stylianou M, Kolobow T. Bacterial colonization of the respiratory tract following tracheal intubationeffect of gravity: an experimental study. Crit Care Med 2003;31(3): 729-737.

5. Zanella A, Cressoni M, Epp M, Hoffmann V, Stylianou M, Kolobow T. Effects of tracheal orientation on development of ventilatorassociated pneumonia: an experimental study. Intensive Care Med 2012;38(4):677-685.

6. Marini JJ, Gattinoni L. Propagation prevention: a complementary mechanism for "lung protective" ventilation in acute respiratory distress syndrome. Crit Care Med 2008;36(12):3252-3258.

7. Gattinoni L, Caironi P, Cressoni M, Chiumello D, Ranieri VM, Quintel M, et al. Lung recruitment in patients with the acute respiratory distress syndrome. N Engl J Med 2006;354(17):1775-1786.

8. Bernard GR, Artigas A, Brigham KL, Carlet J, Falke K, Hudson L, et al. The American-European Consensus Conference on ARDS. 


\section{Spatial Orientation and Mechanical Properties of the Trachea}

Definitions, mechanisms, relevant outcomes, and clinical trial coordination. Am J Respir Crit Care Med 1994;149(3 Pt 1):818-824.

9. Taccone P, Pesenti A, Latini R, Polli F, Vagginelli F, Mietto C, et al. Prone positioning in patients with moderate and severe acute respiratory distress syndrome: a randomized controlled trial. JAMA 2009; 302(18):1977-1984.

10. Guerin C, Gaillard S, Lemasson S, Ayzac L, Girard R, Beuret P, et al. Effects of systematic prone positioning in hypoxemic acute respiratory failure: a randomized controlled trial. JAMA 2004; 292(19):2379-2387.

11. Li Bassi G, Torres A. Ventilator-associated pneumonia: role of positioning. Curr Opin Crit Care 2011;17(1):57-63.

12. Li Bassi G, Marti JD, Saucedo L, Rigol M, Roca I, Cabanas M, et al. Gravity predominates over ventilatory pattern in the prevention of ventilator-associated pneumonia. Crit Care Med 2014;42(9):e620-e627.
13. Alexiou VG, Ierodiakonou V, Dimopoulos G, Falagas ME. Impact of patient position on the incidence of ventilator-associated pneumonia: a meta-analysis of randomized controlled trials. J Crit Care 2009;24(4):515-522.

14. Kolobow T, Cressoni M, Epp M, Corti I, Cadringher P, Zanella A. Comparison of a novel Lycra endotracheal tube cuff to standard polyvinyl chloride cuff and polyurethane cuff for fluid leak prevention. Respir Care 2011;56(8):1095-1099.

15. Zanella A, Cressoni M, Epp M, Stylianou M, Kolobow T. A doublelayer tracheal tube cuff designed to prevent leakage: a bench-top study. Intensive Care Med 2008;34(6):1145-1149.

16. Zanella A, Scaravilli V, Isgrò S, Milan M, Cressoni M, Patroniti N, et al. Fluid leakage across tracheal tube cuff, effect of different cuff material, shape, and positive expiratory pressure: a bench-top study. Intensive Care Med 2011;37(2):343-347. 